Int. J. Electrochem. Sci., 15 (2020) 1548 - 1556

International Journal of

ELECTROCHEMICAL

SCIENCE

www.electrochemsci.org

Short Cmmunication

\title{
Effect of Microstructures on Surface Properties of Electrochemical Machining of Ti-5.6Al-2Zr-4.8Sn-1Mo-0.35Si- 0.7Nd Alloys
}

\author{
Yaowu Zhou ${ }^{1}$, Zhengyang Xu ${ }^{1, *}$, Xuezhen Chen $^{2}$, Yu Tang ${ }^{1}$ \\ ${ }^{1}$ College of Mechanical and Electrical Engineering, Nanjing University of Aeronautics and \\ Astronautics, Nanjing 210016, China \\ ${ }^{2}$ NC Processing Plant, AVIC Chengdu Aircraft Industrial(Group) CO.,LTD.,Chengdu,610092, China \\ *E-mail: xuzhy@nuaa.edu.cn
}

doi: $10.20964 / 2020.02 .37$

Received: 10 September 2019 / Accepted: 21 November 2019 / Published: 31 December 2019

Electrochemical machining (ECM) has been widely used to process high-temperature titanium alloys, however, few studies have investigated the ECM of Ti-5.6Al-2Zr-4.8Sn-1Mo-0.35Si-0.7Nd (Ti60). This study examined the differences in the microstructures of the Ti60 forged with two different methods, focusing on the influences of the material microstructures on the surface morphology produced by ECM. The $\beta$-forged Ti60 reveal a small and staggered grains and a more uniform distribution of the $\alpha$ and $\beta$ phases, and the surface morphology produced by ECM is better than that of the conventional forged Ti60. ECM experiments of the Ti60 were also carried out to analyze the influence of the current density on the surface roughness. The results show that the surface roughness of the Ti60 produced by ECM is adversely affected when the current density is either small or increases considerably. The best surface quality of the two kinds of Ti60 is obtained when the current density is about $50 \mathrm{~A} / \mathrm{cm}^{2}$.

Keywords: Electrochemical machining, Ti-5.6Al-2Zr-4.8Sn-1Mo-0.35Si-0.7Nd, Microstructure, Current density

NOMENCLATURE

$\mathrm{ECM}=$ Electrochemical Machining

FULL TEXT

(C) 2020 The Authors. Published by ESG (www.electrochemsci.org). This article is an open access article distributed under the terms and conditions of the Creative Commons Attribution license (http://creativecommons.org/licenses/by/4.0/). 